\title{
ARTE, CULTURA E CIDADANIA DO PONTO DE VISTA DE MOVIMENTOS INDÍGENAS
}

\author{
Wilson Sousa Oliveira ${ }^{1}$
}

\begin{abstract}
Resumo: Trata-se de um trabalho em que se põe em discussão algumas questões relacionadas à arte, cultura e cidadania entre os indígenas. Tidos como minorias étnicas, inseridos e renegados dentro dos moldes de configurações do mundo capitalista. Alheios às influências que o Imperialismo tentam lhes impor. Traz-se para compor esse debate, principais obras: "A sociedade contra o Estado"(1970); de Pierre Clastres, "O índio brasileiro: o que você precisa saber sobre os povos indígenas no Brasil de hoje" (2006) do Professor Gersem Luciano.
\end{abstract}

Palavras-chave: Arte, Cultura, Dominação, Estado.

\begin{abstract}
Referring to a work in which it discusses some questions issues related to art, culture and citizenship among indigenous. Taken as ethnic minorities inserted and renegated within the set molds of the capitalist world. They remain outside the influences that imperialism tries to impose them. In order to compose this debate main literary works were used: "A sociedade contra o Estado"(1970); de Pierre Clastres, "O índio brasileiro: o que você precisa saber sobre os povos indígenas no Brasil de hoje" (2006) do Professor Gersem Luciano.
\end{abstract}

Keywords: Art, Culture, Domination, State.

\section{INTRODUÇÃO}

Sabe-se da riqueza artística e cultural que é tocar em questões indígenas no Brasil: país fruto das campanhas expansionistas territoriais do século XVI. Pelos anos de 1500 quando os portugueses aqui chegaram, o território hoje chamado Brasil era habitado por cerca de mil povos indígenas diferentes, aproximadamente, esse número chegava a 5 milhões de nativos. Atualmente, calcula-se que apenas 400 mil índios ocupam o território brasileiro. São cerca de 200 etnias e 170 línguas.

Pensar a questão indígena no Brasil, nunca deve-se perder de vista a construção histórica ao longo de tantos anos de dizimação. Necessário, ainda, se faz rever o espaço geográfico, atentar-se para a série de valores artísticos e culturais que lhes foram levados por força a a-

1 Professor de Língua Portuguesa e Literaturas. Mestre em Crítica Cultural pela Universidade do Estado da Bahia (UNEB), Dep. de Educação II — Alagoinhas. Endereço eletrônico: sowwsa@ hotmail.com. 
bandonarem e/ou esquecerem: línguas, usos e costumes. Debater o lugar do índio na sociedade brasileira e espargir o olhar sobre tudo o que lhe aprisiona, se constitui num exercício de revitalização, como também é um esforço em trazer à tona as expressões culturais de uma minoria étnica, colocada num canto, imposto pelas vias do sistema capitalista.

Preocupante também é, o fato de a educação brasileira desde tempos jesuíticos, ter participado da história oficial e também em termos culturais, a lógica adotada sempre se reportou à ocidental/cristã voltados aos interesses capitalistas. Neste sentido, cabe contextualizar essas relações sociais que se estabeleceram envolvendo colonizadores e indígenas no Brasil no intuito de perceber como se deu a produção desses valores/preconceitos culturais que, significativamente, muito tem contribuído para as relações autoritárias e excludentes, impostas pelas classes dominantes no Brasil.

Bem certo é que os resultados colhidos ante essas relações históricas estabelecidas entre colonizadores e povos indígenas, revelaram a construção de valores autoritários e etnocêntricos - infelizmente, ainda presentes na sociedade brasileira, contribuindo significativamente na consolidação com práticas de fortalecimento à desigualdade e à injustiça social.

O termo cultura pensado aqui nesse trabalho, passa pela compreensão de formas ou modelos de organizações econômicas, relações sociais, políticas, práticas artísticas, corporais, religiosas, usos, costumes, modos de vida etc... Para Chauí (1996), o termo cultura é pensado de um modo em que se diverge de como se compreendia na ótica Iluminista. Para o Iluminismo, Cultura é uma forma de avaliar o quanto uma sociedade é civilizada. Cultura, nesse sentido passa a ser compreendido como um conjunto de práticas artísticas, científicas, filosóficas predominando a existência de uma hierarquização de valores de cada indivíduo ou classe na sociedade. Logo, o modelo de referência era da cultura capitalista da Europa Ocidental. Ainda, Chauí (1996),

Em sentido amplo, Cultura é o campo simbólico e material das atividades humanas [...] Em sentido restrito, isto é, articulada à divisão social do trabalho, tende a identificar-se como posse de conhecimentos, habilidades e gostos específicos, com privilégios de classe, e leva à distinção entre cultos e incultos de onde partirá a diferença entre cultura letrada-erudita e cultura popular. (CHAUI, 1996, p. 14)

Já em Canclini (1983), o termo Cultura é pensado de forma de: 
al, ou seja, cultura diz respeito a todas as práticas e instituições dedicadas à administração, renovação e reestruturação do sentido (p. 29).

Partindo-se dessas reflexões, o termo passa a referir-se a diferentes culturas, e nesse sentido, as relações sociais, (que também são políticas), estabelecidas entre os diferentes grupos étnicos numa mesma sociedade, no caso do Brasil, mesmo remetendo a estruturas mentais da cultura dominante, elas se processam inseridas em estruturas materiais que lhe produzem sentido. Logo, se torna compreensível, embora a sociedade brasileira seja pluriétnica, onde, os 215 grupos indígenas têm culturas diferenciadas, são os fatores sociais - políticos e econômicos - de maior autonomia determinando essas relações as quais são representadas por uma única cultura, a dominante.

A questão indígena no Brasil se insere nesse contexto de desigualdade e injustiça social. País fruto dos interesses mercantilistas do início do século XVI, importa olhá-lo sob a perspectiva de quem teve seus principais elementos culturais de origem corrompidos, aniquilados e destruídos ao longo de tantos anos de história. A história do Brasil acaba por ser testemunha de intervenções sistemáticas de uma determinada classe social que, lançando mão de seu poder econômico e mentalidade mercantilista, impôs à maioria da população uma cultura etnocêntrica e fragmentadora, destruidora de relações sociais organizadas sob outras perspectivas e outra lógica de modos próprios de ser e de estar no mundo.

\section{O ESTADO COMO AGENTE DE DOMINAÇÃO}

Discute-se nesses anos todos de múltiplas transformações sofridas pelo mundo, o papel do Estado, suas formas de organização e de atuação... Apesar de reconhecer a enorme influência do poder do Estado na vida da humanidade, na mesma proporção torna-se objeto de preocupação a conciliação e a eficiência dele na preservação dos direitos fundamentais da pessoa humana.

À ideia de Estado liga-se a presença da burguesia, capitalismo, acúmulo de riquezas e organização social. Antagonicamente pensando, do outro lado, à figura do Estado se reporta à ideia daquele que atua como agente de força, poder e dominação na tentativa de resolução dos conflitos da sociedade moderna. Logo, nesse interim, entra em discussão a questão da liberdade. O Estado moderno, sucessor do absolutismo é resultado da experiência histórica de que essa liberdade formal onde grupos, pessoas e organizações sofrem profundas discriminações, 
tiram-lhes a chance de acesso aos benefícios proporcionados pelas invenções da Inteligência humana e pela dinâmica da vida social.

A burguesia no controle da força estatal assume o controle dos meios de produção pondo o dinheiro em circulação em que se interessa o lucro, controle dos sistemas de produção e a expansão dos negócios. Porém, é preciso ter em conta o Estado como fruto da criação humana. Com isso, pode não ser bem ou mal em si, mas poderá ser o que for, quando as pessoas o controlarem. Abrem-se as discussões de Clastres (1970) acerca da presença/ausência do Estado em diversas sociedades, em sua obra "A Sociedade Contra o Estado." Segundo esse, é impossível pensar a sociedade primitiva e sua ligação a controles, dominação, poder, lucro e riqueza. Ainda, não há exploração (explorados e exploradores). Na outra face, divisão social, exploração, riquezas e opressão: a figura do Estado moderno se faz assim operar.

A escola e a educação vigente no país reproduzem uma visão, pois valores artísticos e culturais são pensados pela ótica de representantes de uma classe dominante. Segundo Canclini (1983, p. 74), cada sociedade é uma totalidade estruturada, cada uma de suas partes possui sentido em relação com as outras, e se reforçam mutuamente. A classe dominante, a fim de realizar e por em prática sua dominação aparentemente externa aos grupos minoritários e a hegemonia diante dos grupos étnicos, procura quebrar a unidade e a coesão desses grupos, destruindo o significado que os objetos e as práticas possuem para cada comunidade.

A escola, desde tempos jesuítas tem contribuído para a consagração de um modelo cultural dominante (a do homem branco), por reproduzir tal modelo de pensamentos sobre valores artísticos e culturais. Assim, os representantes de etnias como afro-indígenas acabaram por ter seus direitos e espaços na sociedade, nos livros didáticos e outros, reduzidos ou desprezados.

O grande desafio dos povos indígenas é como garantir definitivamente e em determinadas condições sociojurídicas ou de cidadania o seu espaço na sociedade brasileira contemporânea, sem necessidade de abrir mão do que lhe é próprio: as culturas, as tradições, os conhecimentos e os valores (LUCIANO, 2006, p. 85).

Inserido no contexto capitalista de trabalho, renda e produção, imediatamente, o indígena foi reprovado por não corresponder às expectativas operantes desse mercado nos anos do Brasil colônia. Fácil, assim, foi perceber que os detentores do poder rotulariam o indígena com todos os predicativos a ponto de lhes conceituarem como avessos aos anseios do merca- 
Pontos de Interrogação, v. 4, n. 2, jul./dez. 2014

Revista do Programa de Pós-Graduação em Crítica Cultural

Universidade do Estado da Bahia (UNEB), Campus II — Alagoinhas — BA

do mercantilista. Se assim foi, consequentemente, por possuírem expressões artísticas culturais e modos de vida próprios, tais expressões foram e são sufocadas até os dias atuais.

Ao revisitarmos nosso passado, veremos que cerca de 800 povos indígenas desapareceram. Com eles, se foram inúmeras línguas, rituais, seus hábitos alimentares...não nos esqueçamos de que, quando some uma língua, desaparece com ela uma série de valores culturais. Os indígenas não dominavam a escrita. Modos de vida, usos e costumes eram repassados na base da comunicação oral. Quando desaparece um povo com essas configurações, também é aniquilada uma civilização inteira.

Quando Kabengele Munanga, em "Rediscutindo a mestiçagem no Brasil” (2008), toca na questão da mestiçagem como símbolo da identidade brasileira, é enfático em afirmar que o surgimento de uma etnia brasileira, capaz de envolver a gente variada que no País se juntou — passa primeiro pela anulação das identidades étnicas de índios, africanos e europeus. E reitera:

No nosso entender, o modelo sincrético, não democrático, construído pela pressão política e psicológica exercida pela elite dirigente, foi assimilacionista. Ele tentou assimilar as diversas identidades existentes na identidade nacional em construção, hegemonicamente pensada numa visão eurocêntrica. Embora houvesse uma resistência cultural tanto dos povos indígenas como dos alienígenas que aqui vieram ou foram trazidos pela força, suas identidades foram inibidas de manifestar-se em oposição à chamada cultura nacional (MUNANGA, 2008, p. 95).

Dialogando o tempo todo com Darcy Ribeiro, em "Viva o povo brasileiro", Munanga (2008), vai apontando algumas contradições existentes em Darcy quanto à consciência de nossa formação. Esse acredita na existência de uma cultura brasileira mestiça o que segundo Munanga é uma visão unicultural do Brasil. Porém, para Munanga o processo de construção de nossa identidade, é produzida pelo crivo do pensamento do homem branco: "por outro lado, o processo de construção dessa identidade brasileira, na cabeça da elite pensante e política, deveria obedecer a uma ideologia hegemônica baseada no ideal do branqueamento"(p. 95). Para ratificar a grandiosa presença do indígena na nossa formação, Munanga (2008) não hesita em afirmar que o povo brasileiro surgiu do cruzamento de uns poucos brancos com multidões de mulheres índias e negras (p. 97).

A questão da identidade brasileira, pensada a partir do ideal do homem branco é excludente no que diz respeito às manifestações artísticas e culturais das ditas minorias como já mencionado. Porém, ao longo de tantos anos, o posicionamento do Estado brasileiro se firmou através do jogo de intolerâncias, com traços evidentes de separação entre o homem branco e 
não o branco. Darcy Ribeiro, em Viva o povo brasileiro, afirma: "Do nosso ponto de vista, não encontramos sinal de tolerância num regime que, durante quase meio século, manteve separados do berço ao túmulo os brancos e não brancos" (In: MUNANGA, 2008, p. 99). Sabe-se que o modelo de sociedade imposto a ser aceito, é a do homem branco, masculinizada, ocidental, cristã, capitalista.

A Professora e Pesquisadora Claudia Zapata, em "Movimentos indígenas do século XX” ao tocar na questão da alteridade, sua preocupação recai no modo de como abordar o tema questionando em primeiro plano, alteridade com respeito a que e a quem? Menciona-se então que o contraste estabelecido é em relação àquele sujeito metropolitano, insistentemente mencionado como masculino, branco e ocidental; e, para ela, alteridade refere-se a tudo aquilo que propaga distanciamento de uma configuração histórica particular, instalada como a única válida. E, nesse interim, se volta para a questão de dominação e ao modo de como tais manifestações foram subjugadas, inferiorizadas.

\begin{abstract}
Ainda que a outridade ou alteridade nunca tenha sido um tema irrelevante, a diferença está marcada por como essa alteridade é entendida e abordada. Portanto, uma característica de nossa época que me parece relevante é que existe uma sensibilidade crescente que valoriza trajetórias culturais e históricas que não só são distintas, mas que, ainda por cima, foram inferiorizadas num jogo de poder no qual se constitui a superioridade branco/ocidental/capitalista, questão que se encontra na base dos processos de expropriação e pobreza que afetam as sociedades indígenas, constituindo uma desvantagem que tem sua origem (e solução) neste conflito histórico (ZAPATA, 2007, p. $37 / 8)$.
\end{abstract}

Segundo Zapata (2007), transcorrido tantos tempos, e no auge do desenvolvimento dos movimentos indígenas, bem diferente de outros movimentos surgidos no período republicano, atualmente, a bandeira principal é de luta e reivindicação dessas diferenças. Questiona, ainda, ao tocar na questão da inserção do elemento "índio" entre os discursos de alteridade, querendo saber: qual o tipo de alteridade a se exaltar? Menciona-se com preocupação, em primeira mão, “a história escandalosa de atropelos que a estes povos lhes coube viver (p. 38). A discussão de Zapata passa pela questão da historicidade: "pois seu ponto de partida é uma suposição prévia de como são (e deveriam ser) os indígenas, colocando num segundo plano o vínculo com a sociedade na qual estão inseridos...” (p. 38). Refuta o posicionamento de intelectuais desejosos de falarem na questão, aludem do ponto de vista de tudo que se volta apenas para o "tradicional" nessas sociedades. Afirma da questão indígena, não incidir somente no plano cultural. Para além de tal posicionamento, ela sustenta que a "diferença" ou a "outridade" é real, mas não se restringe à cultura, pois 
Está cruzada com essa história imperial, que funda a categoria do que se considera propriamente de índio/indígena e o conflito que a rodeia até hoje. Este cruzamento entre cultura e história é o que me permite entender essa diferença em termos variáveis, cuja forma vai depender da relação particular que se configura entre os indígenas e a sociedade como um todo (ZAPATA, 2007, p. 38).

As reflexões de Zapata (2007), apontam o tempo todo para o campo político. Para ela "a categoria de 'índio' é política, e não cultural como se costuma pensar, ainda que o elemento cultural seja um componente relevante, utilizado nos mecanismos de inferiorização desses coletivos'(p. 39/40). Destaca a questão indígena como uma “outridade cultural”, inferiorizada pelo ideal do homem branco, ocidental, trazendo em seu bojo valores produzidos pelo sistema capitalista excludente dessas minorias. E há de se entender essa "diferença ou "outridade", segundo ela, porque as sociedades indígenas são destacadas pelo que se manifesta fora delas em relação a esse Ocidente moderno...” (p. 40).

Clastres (1970) destaca como se efetivou o entendimento dos historiadores a esse respeito. Observadores europeus reprovaram veementemente o comportamento dos índios ante a visão europeia sobre trabalho. Inexistia para os indígena o trabalho como uma necessidade. A visão decorrente disso, é que, para o europeu, a civilização da sociedade ocidental se faz mediante a sombra protetora do Estado e a necessidade de dedicação ao trabalho. Trabalhar dois meses a cada quatro anos foi a mais cruel constatação dos europeus em seu entendimento capitalista sobre trabalho e comportamento das sociedades indígenas. A esse respeito, os questionamentos de Clastres são diversos:

\footnotetext{
O bom senso questiona: por que razão os homens dessas sociedades quereriam trabalhar e produzir mais, quando três ou quatro horas diárias de atividades são suficientes para garantir as necessidades do grupo? De que lhes serviria isso? Qual seria a utilidade dos excedentes assim acumulados? (CLASTRES, 1970, p. 136).
}

O intuito de Clastres é nos fazer entender, em termos de organização econômica relativo a essas sociedades, o sentido de subsistência nelas não como um defeito, no momento quando não há incapacidade de se produzir ou em se lidar com suas tecnologias próprias, mas no sentido de essas sociedades recusarem o intenso esforço, a força excessiva no trabalho, pois desconhecem e desprezam o excesso inútil.. Assim, ele ratifica: "para o homem das sociedades primitivas, a atividade de produção é exatamente medida, delimitada pelas necessidades que tem de ser satisfeitas..." (p. 138). 
Logo, a perspectiva de Zapata (2007) e Munanga (2008) está em consonância com Clastres (1970), em “A sociedade contra o Estado". O ideal de Arte, Cultura, no Ocidente é bastante etnocêntrica. Na obra de Clastres (1970) uma outra ideia de organização social, relação de trabalho e produção se ergue ao desmontar as ideias dessas relações, em virtude de que a nossa conceituação está formalizada a partir da ótica capitalista de produção para a acumulação de bens. Tão grave nos é colocada essa questão a ponto de Clastres dizer que cada um de nós traz enraizada, interiorizada, essa certeza de que a sociedade existe para o Estado. (p. 132). Sociedade e Estado são indissociáveis. Assim, o olhar dirigido às sociedades arcaicas, é de maneira negativa. Elas são desenhadas sob o critério da falta: sociedades, sem Estado, sociedades sem escrita, sociedades sem história. Percebe-se a qualificação dada a essas sociedades filtradas sempre com referência ao nosso próprio mundo.

\section{ARTE, CULTURA E EDUCAÇÃO: UMA PROPOSTA ALTERNATIVA ENTRE OS INDÍGENAS}

Notadamente, um dos maiores anseios perseguidos atualmente pela comunidade indígena organizada é eliminar a prática tutelar e paternalista do Estado brasileiro, principalmente dentro dos órgãos do governo. Fugir a essa tutela é sentir-se mais livre na conquista de um espaço e criar, com isso, oportunidades de escolhas melhores e mais justas para si. Torna-se salutar, compreender esses movimentos como lutas em defesa das identidades culturais e da igualdade dos direitos, respeitando suas autonomias e suas especificidades.

\footnotetext{
Ora, os povos indígenas não partilham a mesma língua, a mesma história, os mesmos símbolos, a mesma estrutura social e, muito menos, a mesma estrutura política e jurídica da sociedade brasileira não-indígena, uma vez que possuem símbolos, valores, histórias e sistemas sociais, políticos, econômicos e jurídicos próprios. Eles seguem nas suas aldeias normas particulares que não são as do Estado brasileiro, e que podem mesmo ser contrárias às do Estado (LUCIANO, 2006, p. 87/88).
}

Luciano (2006) sustenta que os povos indígenas constituem parte importante na formação da nação brasileira. Com isso, carregam sentimentos de brasilidade iguais aos de quaisquer outras sociedades, sentimentos e indivíduos que constituem o Estado. Isso não importa culturas, valores, línguas ou símbolos. Segundo ele, há uma outra concepção de cidadania a ser superada no tocante às questões indígenas. É aquela, conforme os cientistas sociais, caracterizam a cidadania temporalizada e territorializada. Esta concepção liga o cidadão a um determinado espaço de tempo de uma sociedade particular e de um território delimitado sob o 
Pontos de Interrogação, v. 4, n. 2, jul./dez. 2014

Revista do Programa de Pós-Graduação em Crítica Cultural

Universidade do Estado da Bahia (UNEB), Campus II — Alagoinhas — BA

comando de um poder central, o Estado. Logo, de acordo essa análise, o Estado aparece como mais um entrave de conquistas para a etnia indígena, pois não reconhece o direito a terra pleiteada por grupos.

Em função deste princípio de soberania territorial, os índios não poderiam ser cidadãos, já que não
possuem a propriedade de suas terras, mas tão-somente o direito de posse e de uso exclusivo dos
recursos naturais nelas existentes, por força do sistema político e jurídico do Estado brasileiro que
não aceita a existência de propriedade coletiva, como são as terras indígenas (LUCIANO, 2006, p.
88).

Segundo o Artigo 1 do Pacto Internacional dos Direitos Civis e Políticos, Sociais e Culturais, autonomia é uma forma do exercício do Direito à livre autodeterminação dos povos o que implica o reconhecimento de autogoverno comunitário no âmbito de um estado nacional.

\footnotetext{
Autonomia, portanto, não é o mesmo que independência nem envolve soberania, elementos indispensáveis na integração de um Estado. Autonomia é uma entidade menor no interior de uma entidade maior única e soberana. É também uma forma de distribuição de competências nos distintos níveis de organização do governo e em torno de variadas atribuições políticas, econômicas, sociais e culturais (LUCIANO, 2006, p. 94).
}

Segundo a Professora e pesquisadora Nietta Lindenberg Monte, em seu artigo "E agora, cara pálida? Educação e povos indígenas, 500 anos depois” — a UNESCO já declarara a importância o uso das línguas maternas de qualquer povo na educação escolar. Inicia-se uma série de reorientações nos fundamentos técnicos e políticos passando a influenciar discursos oficiais acerca da educação escolar para sociedades indígenas. Em 1957, a Convenção da Organização Internacional do Trabalho (OIT), de número 107, e sua revisão a partir dos anos 70, resultou em 1989 na convenção 169, relativa à proteção e à integração das populações indígenas em países independentes (p. 120). Ultimamente, os mais importantes organismos internacionais: A Organização dos Estados Americanos (OEA) e a Organização das Nações Unidas, (ONU) desempenha papel importante na perspectiva em debater políticas e desenvolver ações voltadas para questões culturais das ditas minorias. "Ajudaram na defesa da manutenção e revitalização lingüística e cultural das sociedades indígenas, a ser propiciada também pela escola, dentro dos estados multiculturais, conceituados em nossos dias em seus diversos matizes, dos marcos mais liberais aos mais pluralistas" (idem).

Os estudiosos apontam o ano de 1988, com a mais recente Constituição Federal promulgada, o marco inicial de levantamento de debates e oficialização de proteção por parte do Estado à questões indígenas no Brasil. O discurso da legislação brasileira está atrelado a esse conjuntura dos discursos internacionais. "São reconhecidas aos índios sua organização social, 
Pontos de Interrogação, v. 4, n. 2, jul./dez. 2014

Revista do Programa de Pós-Graduação em Crítica Cultural

Universidade do Estado da Bahia (UNEB), Campus II — Alagoinhas — BA

costumes, línguas e tradição e os direitos sobre as terras que tradicionalmente ocupam, competindo à União demarcá-las, proteger e fazer respeitar todos os seus bens" (Constituição Federal Brasileira, 1988, Capítulo VIII, Art. 231). Os direitos educativos e linguísticos também passam a estar garantidos pelo poder público, no capítulo sobre o Ensino Fundamental, pelo qual "é facultado às comunidades indígenas a utilização de suas línguas maternas e processos próprios de aprendizagem" (idem, Art. 210). A Constituição de 1988 traz o seguinte apontamento:

Os currículos do ensino fundamental e médio devem ter uma base nacional comum, a ser complementada, em cada sistema de ensino e estabelecimento escolar, por uma parte diversificada, exigida pelas características regionais e locais da sociedade, da cultura, da economia e da clientela - $\mathrm{O}$ ensino da História do Brasil levará em conta as contribuições das diferentes culturas e etnias para a formação do povo brasileiro, especialmente das matrizes indígenas, africana e europeia. (Art. 26, § $4^{\circ}$ - Seção I - Cap. II — LDB — CONSTITUIÇÃO DA REPÚBLICA DO BRASIL, 1988).

Além do mais, a Lei de Diretrizes e Bases da Educação nacional, de 1996 descortina uma série de deveres assegurando ao Estado brasileiro o dever de:

I - proporcionar aos índios, suas comunidades e povos, a recuperação de suas memórias históricas; a reafirmação de suas identidades étnicas; a valorização de suas línguas e ciências; II - garantir aos índios, suas comunidades e povos, o acesso às informações, conhecimentos técnicos e científicos da sociedade nacional e demais sociedades indígenas e não-índias. Art. 79 - A União apoiará técnica e financeiramente os sistemas de ensino no provimento da educação intercultural às comunidades indígenas, desenvolvendo programas integrados de ensino e pesquisa. $\S 1^{\circ}$ - Os programas serão planejados com audiência das comunidades indígenas. $\S 2^{\circ}-$ Os programas a que se refere este artigo, incluídos nos Planos Nacionais de Educação, terão os seguintes objetivos: - fortalecer as práticas sócio-culturais e a língua materna de cada comunidade indígena; - manter programas de formação de pessoal especializado, destinado à educação escolar nas comunidades indígenas; - desenvolver currículos e programas específicos, neles incluindo os conteúdos culturais correspondentes às respectivas comunidades; - elaborar e publicar sistematicamente material didático específico e diferenciado. (Lei No 9.394 de 20 de Dezembro de 1996).

Nesse sentido, os documentos do estado brasileiro(a Lei de Diretrizes e Bases da Educação e a Constituição Federal) fazem alusões à História dos povos indígenas lembrando as contribuições desses para nossa formação, realça seus valores, usos, costumes e práticas, como também tem demonstrado preocupação em formar escolas bilíngues, respeitando a língua materna de cada povo, preparando material didático que se adeque às manifestações culturais das diversas tribos; ainda, há um intenso debate pela formação de professores e articuladores indígenas, ligados a movimentos socioculturais com atenção e reflexão em práticas educacionais, aptos a estabelecerem diálogos no encontro intercultural das gentes em suas diferenças e peculiaridades étnico-culturais. 
No entanto, um outro apontamento como rota de fuga, se desponta no estado do Acrecom a criação da Comissão Pró-Índio do Acre (CPI/AC). Segundo Monte (2000), esse órgão foi responsável pela reformulação, sistematização e regularização das primeiras propostas curriculares alternativas para as escolas indígenas, "respeitando as demandas políticas e as orientações curriculares e linguísticas das sociedades indígenas participantes" (p. 127). E reitera:

\begin{abstract}
Alternativo ao Estado, o projeto educacional da entidade, durante seu trajeto contínuo de duas décadas, buscou a conquista, desde seus primórdios, do reconhecimento de órgãos públicos de estado e federais. Lutou pela incorporação dos então "monitores indígenas" e de suas escolas na rede estadual de ensino público, mas esforçando-se por assegurar-lhes a autonomia curricular e administrativa (MONTE, 2000, p. 127).
\end{abstract}

Para serem mais ousados, a Comissão Pró-Índio do Acre (CPI/AC), em 1985, firma uma parceria com o Estado para garantir, a médio prazo, o projeto de formação de Professores Indígenas. Como também dar continuidade a publicações de materiais didáticos destinados às escolas das florestas, de autoria de Professores Indígenas em formação. A CPI/AC envolvida na formação didática dos professores, incluiu também nesse projeto viagens de acompanhamentos pedagógicos às escolas da aldeias "entendidas como importante momento de formação dos professores indígenas e da própria equipe de docentes e assessores educacionais do projeto" (p. 127). Nesse interim, consegue mobilizar instituições de renome e ganhou apoio da Secretaria de Educação do Estado do Acre, Fundação Nacional do Índio (ainda responsável, na ocasião, pelas políticas nacionais de educação indígena) e da Fundação Nacional PróMemória, do Ministério da Cultura (que apoiava, na época, algumas ações de educação escolar culturalmente relevantes). O estado do Acre preparava-se para a contratação definitiva de Professores indígenas, porém eram aqueles professores formados pela CPI/AC e a inclusão dessas escolas no sistema estadual do Acre, como categorias diferenciadas e específicas. A CPI/AC consegue flexibilização e regulamentação dos currículos indígenas e a contratação de Professores indígenas pelos estados brasileiros. Com essa ação, o estado do Acre torna-se modelo referencial, político e educacional no Acre e em outros estados.

Interessante conquista se fez mesmo no sistema de contratação/seleção dos Professores indígenas. Estabeleceu-se um sistema diferenciado de seleção e avaliação para o Magistério Indígena em algumas secretarias. Em 1992 realiza-se o primeiro concurso para Professores índios, com conteúdos relacionados ao currículo bilíngue. Ainda, conseguiu-se a aprovação pelo Conselho Estadual de Educação da Proposta Curricular Bilíngue e Intercultural para as 
escolas indígenas da região, apresentada pela equipe da Comissão Pró-Índio do Acre, em Junho de 1993. Em 1998, sob coordenação da Professora Nieta Lindenberg Monte, foi aprovada a Proposta Curricular de Magistério Indígena Bilíngue, de nível médio. A CPI/AC se firma, pois:

\footnotetext{
Algumas implicações desse convênio no campo institucional podem ser apresentadas: a aceitação do princípio da autonomia curricular e da descentralização do Estado com relação a uma parte das políticas públicas educacionais, garantida a responsabilidade e apoio de uma organização nãogovernamental e do movimento indígena.
}

Quanto aos Professores indígenas, esses passam a existir como funcionários públicos, mas não perdem seus vínculos e compromissos com as comunidades. Por tais engajamentos, recebem o qualificativo de "Funcionários da Floresta". Monte (2000), afirma: "tal expressão bastante original, foi inventada entre eles." Além do mais, os cursos de formação para os Professores indígenas são diferenciados daqueles oferecidos para o Magistério regular, rural e urbano, segundo ela, dá-se "sob a responsabilidade técnica de uma entidade da sociedade civil de cunho laico.”(p. 128). "A escola que a gente quer é a escola do prazer, aquela que a gente pode vir todos os dias e nunca sinta vontade de ir embora. Não queremos uma escola que só tenha mais cadeiras, quadro-negro e giz, mas uma escola da experiência, da convivência e da clareza” (Creuza Kraho, MEC, 1998, p. 53).

Segundo Monte (2000), desde seu início o trabalho, por sua natureza, intitulou-se "Uma Experiência de Autoria" e explica:

O conceito de "experiência" expressava uma linha de ação de caráter alternativo, processual e local, visando atender a algumas das demandas indígenas por políticas educacionais na região. O conceito de "autoria" ocupava o lugar de uma metáfora e expressava uma linha de trabalho filosófico e político: aos professores indígenas, em articulação e consulta junto à sua comunidade, cabia a responsabilidade das decisões relativas à escola, nos aspectos administrativos, políticos e pedagógicos. Buscava-se a vivência responsável no âmbito do educacional do tão proclamado conceito e valor da autonomia e da autodeterminação (p. 128).

Pode-se afirmar que a grandiosidade desse trabalho se configura por seu grau de autonomia e desvinculação da tutela do Estado. Agora, novos e velhos conhecimentos são selecionados como conteúdos de aprendizagens para si e para os/as alunos/as. A base do novo currículo educacional em construção é marcada e firmada nas próprias vozes faladas e escritas dos membros de cada comunidade. "Aí eu penso numa escola-maloca, voltada para a realidade da vida e da situação da comunidade. No livro didático, ao invés de uma escola de colarinho, teria um índio pescando" (Higino Tuyuca, in MEC, 1998, p. 26). 
Pontos de Interrogação, v. 4, n. 2, jul./dez. 2014

Revista do Programa de Pós-Graduação em Crítica Cultural

Universidade do Estado da Bahia (UNEB), Campus II — Alagoinhas — BA

Assim, segundo Monte(2000), um novo modelo de gestão educacional começa a se levantar. O princípio maior firma-se pela promoção de uma educação diferenciada. Distantes estão os modelos de integração e cristianização anteriores. São novas propostas de flexibilização curricular. O imperativo das novas propostas passam e fundamentam-se nas especificidades étnico-linguísticas das sociedades indígenas envolvidas, nos diversos contextos e histórias de contato, e no potencial de participação política dos autores (p. 128).

Diante do exposto até aqui, poderíamos tomar o lugar dos movimentos indígenas - toda a sua produção, vontade e desejos - como potente máquina de guerra na desarticulação, agindo na condição reacionária de resistência ante ao modelo fetichista operante. Tais movimentos se constituem em linhas de fuga nesse contexto de cerceamento e dominação. Os valores artísticos e culturais indígenas, sua questão de cidadania estão para além de um pensamento ocidentalizado de concepção dada sem questionamentos e sem o levantamento da dúvida.

Há de se maquinar dentro dessa configuração "arrumada" sobre outras possibilidades, sobre outros modos, outras linhas de fuga. O teórico Bhabha (1998) já sinaliza sobre o perigo dos discursos hegemônicos sobre essa "normalidade" em um desenvolvimento totalmente irregular e histórias diferenciadas entre nações, comunidades, povos... Pois notadamente, percebe-se que cultura predomina e como as demais foram subjugadas. E em se tratando da representação artísticas do negro e do índio, pouco se encontra em livros de arte, em movimentos culturais e mesmo na conjuntura componente da educação brasileira. Geralmente, quando o índio aparece, é em situação equilibrada, harmônica e pacífica com o branco. Aspecto cultural, totalmente modificado na arte.

Já no século XIX, a formação do Estado brasileiro se dá em conformidade com os interesses da elite dominante como expressão dos interesses das elites colonizadoras. O novo Estado criado e organizado a partir das ideias liberais da Revolução Burguesa, excluiu os povos indígenas, assim como os negros de seu projeto político. Segundo Luciano (2006), desde então, o Estado brasileiro tem se tornado um fator negativo para a continuidade dos projetos sociais e étnicos dos povos indígenas, condenando-os a um congelamento político, jurídico, social e econômico (p. 95). Em consequência disso, os povos indígenas tem sido impedidos de influenciar a vida pública com suas normas organizativas, seus códigos culturais específi$\cos$. 
Foucault (2002), com o livro A ordem do discurso traz uma rica contribuição para esse trabalho. Pois ele vai questionar toda a "ordem de um sistema" e clama por uma alteração da ordem do dia. Segundo esse teórico francês é preciso "questionar a nossa vontade de verdade", e o começo é com a quebra dos "rituais". E a partir do momento que o professor de arte e outros instigar aos alunos para enxergarem além das imagens, os percursos que fizeram com que aquela imagem estivesse naquele espaço, bem como a quem ela está servindo e de que forma? Quando a "quebra dos rituais" como o pintar, colar e pontilhar acontecer, irá fortalecer nas nossas aulas de artes e os livros de arte e novos currículos tomarão novos direcionamentos, como defende Deleuze e Guattari (1995) teremos em mãos uma “máquina de guerra” revolucionária.

Nos reportando ao pensador da interculturalidade, Homi Bhabha, a educação escolar indígena pode ser vista como um entre-lugar de acontecimento de diálogos educativos, favorecendo, assim, o acontecimento de aprendizagens que valorizem as relações de interculturalidade e de desconstrução das relações de dominação e de imposição de subalternidades.

Fugir à dominação ou a práticas idealizadas por uma elite que concebe educação, arte e cultura, educação e cidadania por um único viés, tem de ser o elemento operante dentro da educação nacional. No mais, cabe fazer percorrer o nosso olhar contra a dominação e o cerceamento que são marcas da figura do Estado. Segundo Meliá (1997 In: Bonin, 1998, p. 41), assumir tal postura não significa isolamento ou rejeição de tudo proveniente da cultura hegemônica, mas o estabelecimento do dialogo no sentido pleno: ao lutar pela autonomia, os povos indígenas reivindicam a possibilidade de conhecer o discurso revelado e velado da sociedade hegemônica. Pretende estabelecer com ela outro tipo de relação, diferente da imposição ou da negação.

\section{REFERÊNCIAS}

BHABHA, Homi K. (1998). O pós-colonial e o pós-moderno. A questão da agência. In: . O local da cultura. Belo Horizonte: UFMG.

BONIN, Iara Tatiana. A Ação Educativa na Tradição Kambeba: construindo significados para a escola. Brasília, 1998. Projeto de Dissertação (Mestrado em Educação) Faculdade de Educação, Universidade de Brasília, 1998.

CANCLINI, Néstor García. As Culturas Populares no Capitalismo. Tradução de Cláudio Novaes Pinto Coelho. São Paulo: Brasiliense, 1983. 
CHAUI, Marilena. "Introdução como de Práxis" e "Ainda o Nacional e o Popular". In: Conformismo e Resistência — aspectos da cultura popular no Brasil. 6a Ed. São Paulo: Brasiliense, 1996.

CLASTRES, Pierre. A Sociedade Contra o Estado. 1970.

DELEUZE, Gilles. GUATTARI, Félix. Introdução: rizoma. In: Capitalismo e esquizofrenia. Trad.Ana Lúcia Oliveira, Rio de Janeiro: Ed. 34, 1995.

FOUCAULT, M. A Ordem do Discurso. São Paulo: Loyola, 2002 .

LUCIANO, Gersem dos Santos. O Índio Brasileiro: o que você precisa saber sobre os povos indígenas no Brasil de hoje. SECAD - Secretaria de Educação Continuada, Alfabetização e Diversidade. MEC, Brasília, 2006.

MELIÁ, Bartolomeu. Ação Pedagógica e Alteridade: por uma pedagogia da diferença. In: CONFERÊNCIA AMERÍNDIA DE EDUCAÇÃO - AMERÍNDIA: tecendo os caminhos da educação escolar. Anais da Conferência Ameríndia de Educação e Anais do Congresso de Professores Indígenas do Brasil. Cuiabá, MT: Secretaria de Estado de Educação/Conselho de Educação Escolar Indígena de Mato Grosso, 17 e 21 de novembro de 1997, p. 21-28.

MONTE, Nietta Lindenberg. E agora, cara pálida? Educação e povos indígenas, 500 anos depois. Rev. Bras. Educ.[online]. n. 15, p. 118-133, 2000.

MUNANGA, Kabengele. Rediscutindo a mestiçagem no Brasil. Autêntica Editora LTDA, Belo Horizonte, 2008.

ZAPATA, Claudia. Movimentos Indígenas do Século XX. Aletria, Volume 16 - Julho/Dezembro, 2007.

Recebido em: 19 de outubro de 2014.

Aceito em: 20 de novembro de 2014. 
